\title{
The employment of terrestrial laser scanner in cultural heritage conservation: the case study of Vallinotto Chapel in Carignano-Italy
}

\author{
Garnero Gabriele • Godone Danilo • Bacciocchi Marco
}

Received: 5 March 2009/Accepted: 16 February 2010 /Published online: 12 March 2010

(C) The Author(s) 2010. This article is published with open access at Springerlink.com

\begin{abstract}
Terrestrial laser scanner is a key methodology in cultural heritage survey, as it allows representing objects with high accuracy from the geometric point of view but allows also generating graphic representation of high visual impact for public (nontechnical) audience. The case study is a Vittone's chapel, located in Carignano (Turin Province, NW Italy) characterized by a complex internal structure due to multiple layers of arches and other structures. The role of these features is not only structural but also figurative in order to represent, in the Chapel, the different levels of celestial hierarchy. The Chapel is now involved in a documentation project and thanks to the presence of scaffolding structures different scans have been carried out with an Optech-ILRIS 3D instrument. In the same time, using a calibrated digital camera, different pictures of the building have been taken. Scans have been accomplished at three different levels, due to scaffolding height, $(10 \mathrm{~m}, 6 \mathrm{~m}$, and ground) in order to obtain a complete survey of the building interior. A second series of scans has then been made in order to measure the exterior of the building. In the same time a classical topographical survey has been
\end{abstract}

G. Gabriele $\cdot$ G. Danilo $(\triangle)$

D.E.I.AFA (Department of Agricultural,

Forest and Environmental Economics and Engineering),

Turin University,

Via Leonardo da Vinci, 44, Grugliasco,

10095 Turin, TO, Italy

e-mail: danilo.godone@unito.it

URL: www.agraria.unito.it/dip/deiafa/homedeiafa.htm

G. Gabriele

URL: www.agraria.unito.it/dip/deiafa/homedeiafa.htm

B. Marco

Codevintec,

Via Labus,

13-20147 Milan, Italy performed, using a no prism Sokkia total station, with the purpose of measuring tie point therefore used to merge the internal and external scans and to assess the alignment phase's accuracy. The final model has then been processed in order to project calibrated images on some test areas through orthoimage generation.

Keywords Terrestrial laser scanner Calibrated images . 3D modeling $\cdot$ Cultural heritage

\section{Introduction}

Artistic notes

The sanctuary of Vallinotto or "Cappella della Visitazione" (1738) is located in the municipality of Carignano, in Turin province.

Arch. Bernardo Antonio Vittone has been appointed, by the banker Antonio Faccio, to build the church, in order to supply spiritual care to his estates' farmers: the chaplain, chosen by Faccio himself or by his heirs, preferably among priest of their kindship, should say Mass every day, confess, and teach catechism "da Santa Croce a San Giovanni" (From Saint Cross to Saint John).

The church shows a sober and elegant appearance, it is not characterized by the usual rural chapel style, it is instead a jewel of baroque architecture enriched with rococo ornament: it invites to the prayer and it is pervaded by a strong sense of religiousness. Inside the church everything is conceived and located with the purpose of suggesting, to the visitor, a faith path.

The light coming from above, from the dome opening like a flower, over the visitors' heads raises their eyes. The light is employed and contemporarily becomes a metaphor 


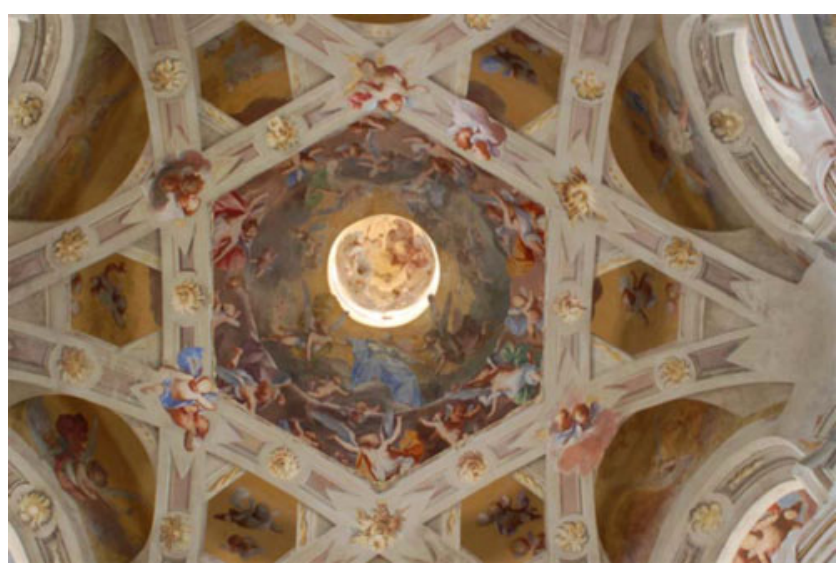

Fig. 1 The spectacular dome "a tre volte l'una sopra l'altra tutte traforate e aperte" (with three vaults, one on top of the other, all perforated and open ), as described by Vittone himself

of the divine: by following the light everyone may reach the Light, as may reach God, our Light.

By entering the remarkable baroque main entrance a path begins: the pilgrim, immersed in faint light as a sinner, is attracted by the light descending from above and by raising his eyes he gazes at the Counter-Reformation Saints (S. Filippo Neri and S. Francesco di Sales at the right side of the entrance; S. Francesco Saverio and S. Carlo Borromeo at its left).

Then, at a higher level, on the counter-dome arches' base, the 12 apostles are represented on a fresco, and moreover, by further raising the eyes the pilgrim gazes at the Divine Triumph: the Angels, the Holy Virgin, and the Holy Trinity.

The perimetrical path is referred to the Sacraments: the Baptism that allows entering the Church, the Confession as a way to reconcile ourselves with God and our fellow creatures, and the Holy Communion in order to praise the Lord. On the two open confessionals (with goat-like feet and on their top the symbol of the Holy Trinity) stand two warnings "adesso sei libero dal peccato" (now you are free from sin) and "non peccare piü" (do not commit a sin anymore) while on the entrance "rifletti, perché fuori di qui potresti trovare qualcosa di peggiore" (meditate, because outside this place you may find something worse) is written.

Frescos on the dome, divided by the structures in order to locate in different sectors celestial hierarchy figures, are ascribed to Pier Francesco Guala, as well as the altar-piece representing the Visitation of the Holy Mary to Saint Elizabeth, currently substituted by a copy for security purposes (the original one is kept at the Opera Piacharitable institution-Faccio-Frichieri in Carignano, owner of the building).

For the same reason, other two features are kept in the same locations, the altar-frontal and the tronetto, representing angles worshipping the Eucharist. It has been made from rare woods, inlayed with ivory and nacre. In the vestry, on a fresco, the gentle "Madonna del latte" (XVI century) is represented, sign of a previous building opposite to the current one, now constituting a unique body; the remarkable fresco is ascribed to a painter nearly contemporary with Macrino (approximately 1500; Fig. 1).

The main feature of the building is the complex composition of arches and vaulted structures built with different purposes, not only structural but also ornamental and scenographic (Fig. 2): these structures are indeed set as a cover of a window series located in the dome, in order to hide the direct light source to the observer, in a way typical of Vittone (Brinckmann 1931; Wittkower 1958; Pommer 1966; Portoghesi 1982).

The chapel is currently involved in a documentary project with the purpose of the exploitation of cultural heritage: with the aim of the execution of interior shooting the dome's fresco has been cleaned, during these operations
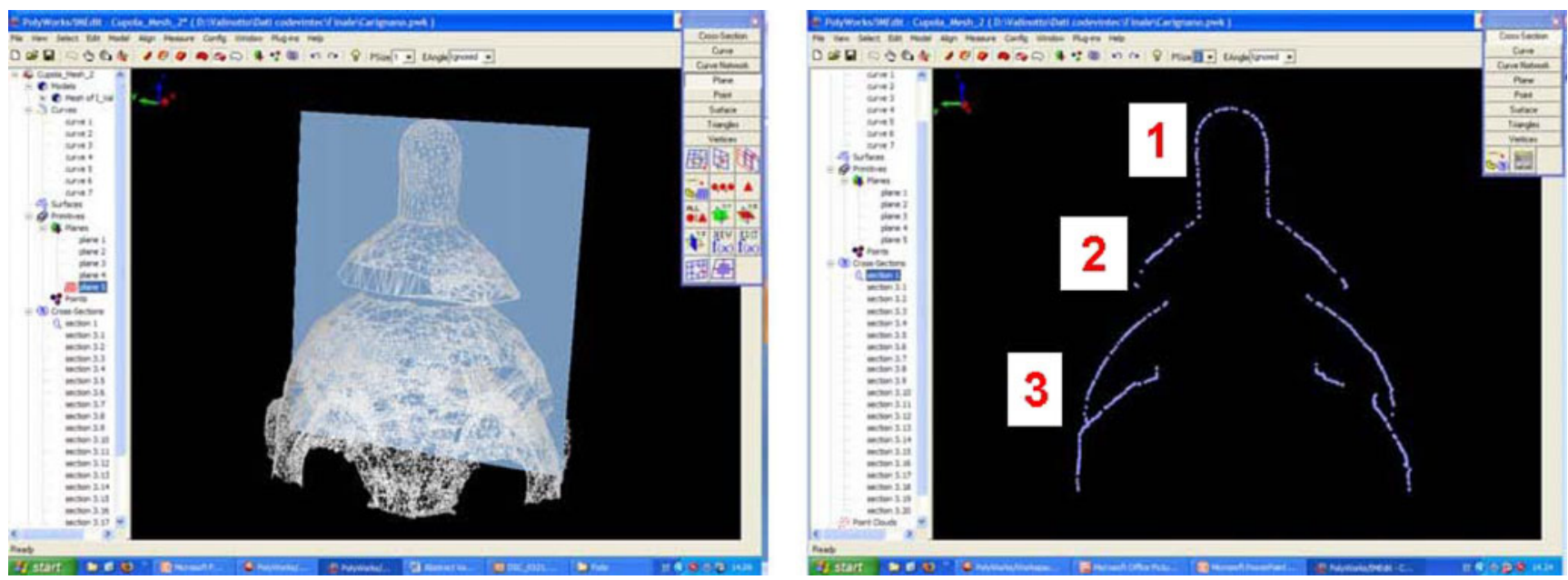

Fig. 2 Internal structure of the dome ( 1 dome's summit, 2 windows, 3 arches) 
the scaffoldings has been used as a support for the survey of the building as described later.

\section{Building survey}

Chapel survey has been accomplished by employing a terrestrial laser scanner, Optech ILRIS-3D ${ }^{\mathrm{TM}}$, equipped with a fully motorized panning and tilting base. In order to reconstruct the three-dimensional model of the building, different measurement sessions have been planned with the aim of measuring the interior and exterior of the church.

The first session, technically the most complex to plan due to the structure particularity, has been subdivided in three different phases, according to the scaffolding height (10 m, $6 \mathrm{~m}$, and ground level or no scaffolding; Fig. 3). In every measuring session different acquisitions have been carried out, varying the position and orientation of the instrument with the purpose of minimizing hidden portion of the structure. The instrument has been controlled by a remote device in order to reduce vibration caused by instrument operators on the scaffolds and consequently to assure enough quality in survey execution.

The external survey has been carried out by placing the instrument in different positions, with different points of view with the purpose of obtaining a complete description of the building. Due to the need of aligning the two models, interiors and exteriors, in a unique one the chapel altar has been surveyed twice, both from the interior and from the exterior sessions - after the removal of the door entrancein order to use it as a join feature of both models.

The altar has been further surveyed with the aim of verifying the accuracy of laser measurements: reflecting targets has been placed on the altar and measured both
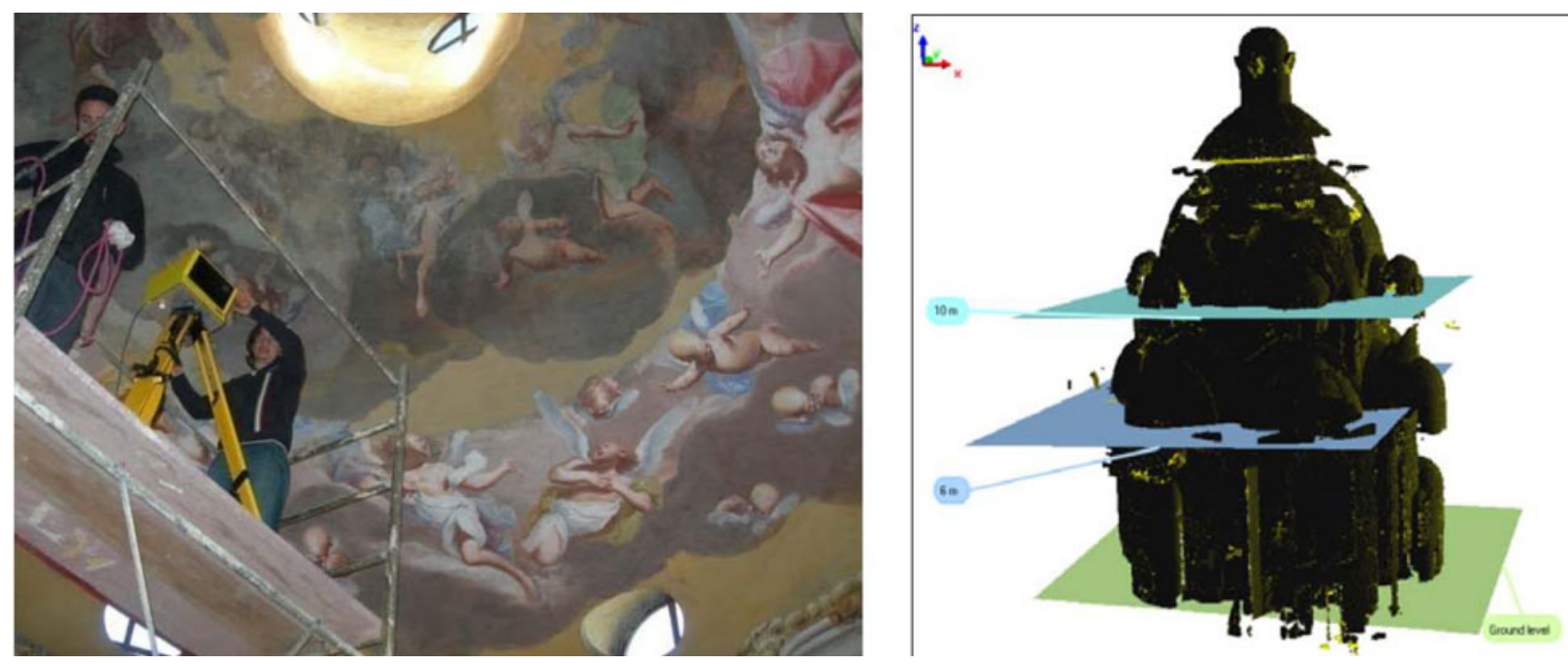

during the laser acquisition and by a traditional topographical survey by employing a no prism total station, Sokkia Set $440^{\mathrm{TM}}$.

During survey sessions, by employing a calibrated digital camera, several shoots have been taken with the purpose of projecting images on the three-dimensional model.

\section{Data processing}

Data obtained from manifold measuring sessions have been imported in Poliworks ${ }^{\mathrm{TM}}$ software where, in the ImAlign module, scans have been aligned by homologous feature collimation in the different point clouds. The first outputs of the process were partial model related to every measurement day. In a second phase two complete models, internal and external, have been generated by a further alignment session: in both cases, a simplification procedure has been carried out, with the purpose of the removal of exceeding points in overlapping areas, between two or more scans. The whole model has then been generated by aligning the interior and exterior one by the collimation of homologous features on altar structure, surveyed in both sessions (Fig. 4).

In the ImInspect module, targets' coordinates have been extracted, from the point cloud, by interpolating circles on points provided with a certain intensity values -i.e., point surveyed on target's reflective surface - and automatic center coordinates computation. Distances between these points have then been statistically compared with those calculated on points surveyed by traditional methods (total station).

Moreover, in some test areas, image projection on dome surface has been carried out (Fig. 5) by the employment of

Fig. 3 Interior survey (left) and scaffolding levels (right) 

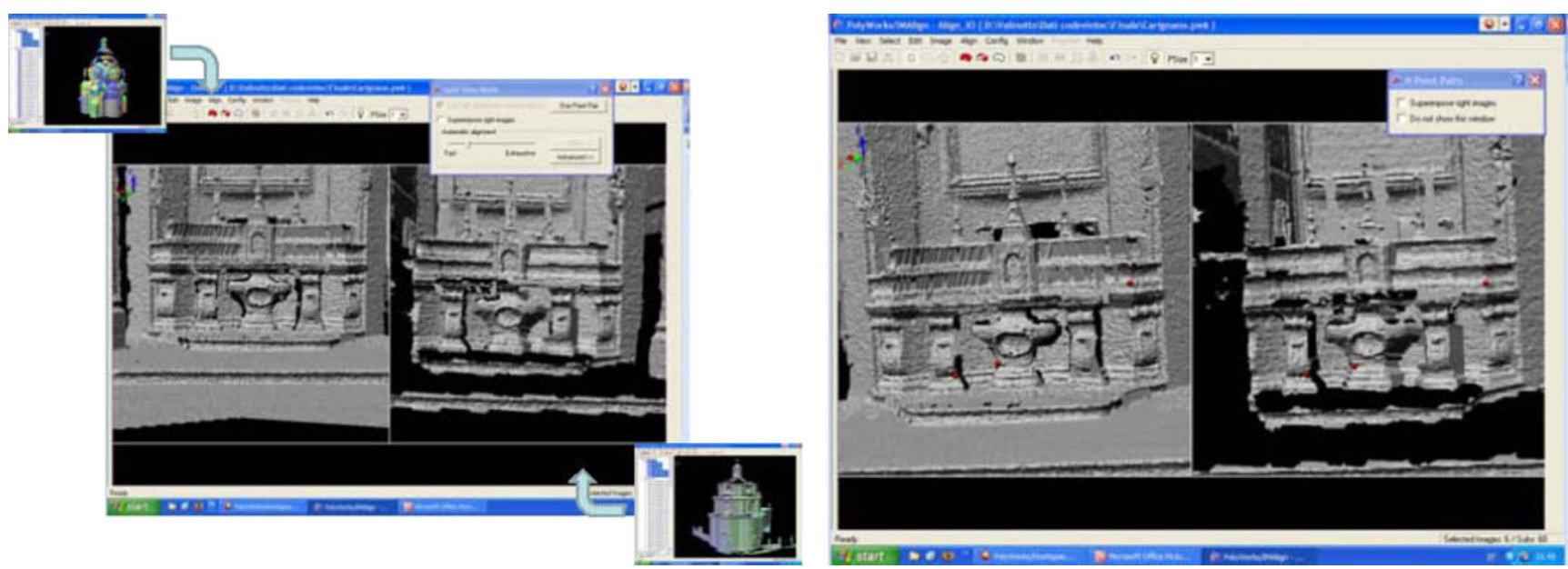

Fig. 4 Alignment procedure of the two models based on altar features

"camera calibration" tool supplied in JRC Reconstructor V2 ${ }^{\mathrm{TM}}$ software. Due to the structure complexity, technical problems have been encountered when projecting images on dome sectors. Because of the presence of arches and other surfaces the individuation of an appropriate point of view to project images was highly difficult. In fact the presence of structures on several planes have always cause occlusions and shadow effects.

The employment of the "virtual scan" tool (Sgrenzaroli and Vassena 2007) provided with the same software has allowed to partially solve the issue by the generation of new surfaces, congruent with the original reference systems, but oriented in the right way to the projection of the image corresponding to the concerned dome sector. The execution of the "virtual scan" on a 3D model, already provided with a projected image, has furthermore allowed to have a remarkable quantity of features, useful for the collimation phase, at subsequent projection phase's disposal.

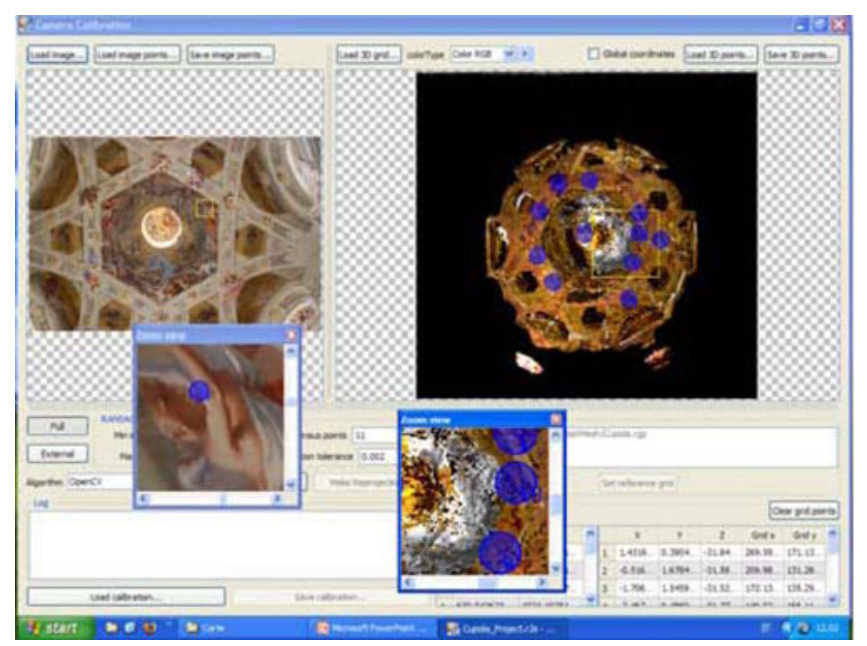

Fig. 5 Projection of calibrated images on three-dimensional model

\section{Results and discussion}

The main result of described phases is the production of a three-dimensional model of the chapel: the employment of the ICP algorithm (Beinat 2006; Besl and Mc Kay 1992; Chen and Medioni 1992) has assured, both in preliminary phases and in the final alignment, an adequate accuracy, below the one declared by the laser manufacturer (Optech).

The alignments between the three internal parts, surveyed at different scaffolding heights, have provided different accuracies. The " $10 \mathrm{~m}$ " and " $6 \mathrm{~m}$ " have been aligned with an overall accuracy of $\pm 10 \mathrm{~mm}$ while the "ground level" has been aligned to the others with respectively \pm 8 and $\pm 7 \mathrm{~mm}$ accuracy, as all the three sectors have overlapping areas. The lower quality in the alignment of two first parts may be due to the shadow effects of the scaffolding and protruding features of the dome structure, like balconies or arches. The whole internal survey has then

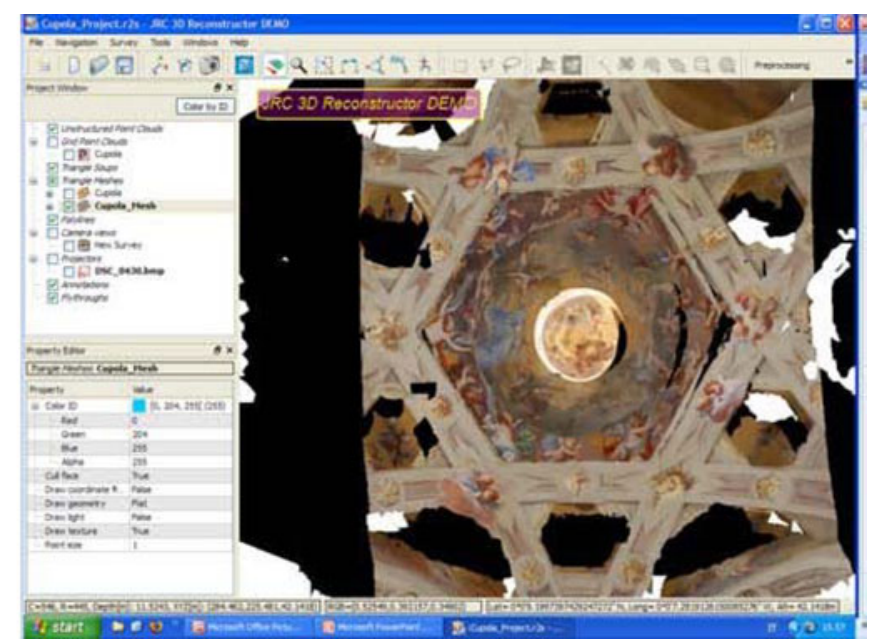


been aligned to the external one obtaining a $\pm 4 \mathrm{~mm}$ accuracy. This results concerns only common features to the two surveys, as the altar or the entrance structure, in other areas, as the dome, the accuracy may result in higher values.

The adopted methodology, and the aim of the work, has allowed avoiding the employment of reflective targets to perform alignments. The survey's purpose is in fact the production of documentary data so a speditive approach has been preferred. The survey has been accomplished in only 3 days of field work with a team of three operators. The data processing has thus required a similar amount of time and has been fulfilled by a single operator. The image projection phase has been carried out in other 3 days with similar modalities as the post-processing one.

During the survey a remarkable amount of point clouds have been measured, the " $10 \mathrm{~m}$ " sector has required seven scans: four with the instrument in a fixed position with the purpose of measuring the dome upper part and three with the instrument mounted on its motorized panning and tilting base to measure the lower part of the dome and the chapel's walls. The other two levels have been measured by the instrument positioned in two survey stations and varying measuring angles with the base and thus collecting up to eight circular surveys and six fixed measures of particular features.

The external survey has been fulfilled from four different positions where at least three scans has been carried out included the one employed to link the internal and external surveys.

A further proof of model quality has been provided by the comparison carried out on targets: the $t$ test has in fact confirmed the lack of significative differences $(p=0.93)$ between residuals (mean $=0.0020$; standard deviation= 0.0093) computed from the two measurement datasets (traditional and laser).

Calibrated image projection has allowed reconstructing meaningful building portions, currently limited to some dome sectors, useful in the production of documentary, divulgative, or project-oriented supports with the purpose of exploiting the cultural heritage.

\section{Conclusions and future developments}

Terrestrial laser scanner technology has proven its effectiveness in solving the described task, assuring a time reduction during surveys and contemporarily guaranteeing an excellent quality in the final result. Instrument output has proven to be relatively user friendly in post-processing phase, with the only one deficiency, the requirement of a high-performance computer, due to the remarkable size of generated files (Fig. 5).

Image projection is still affected by some drawback, because of the difficulty to find the appropriate software tools in order to manage and project-calibrated images on non-plane surfaces: currently the "virtual scan" tool turns out to be promising thanks to its versatility, but the need to join multiple image in a unique support is still an open issue.

Future development of this work is the implementation of plotting tool on the three-dimensional model, but contemporarily employing the chromatic content of projected images, with the purpose of having a three-dimensional design tool to be employed in project tasks.

Open Access This article is distributed under the terms of the Creative Commons Attribution Noncommercial License which permits any noncommercial use, distribution, and reproduction in any medium, provided the original author(s) and source are credited.

\section{References}

Beinat A (2006) Tecniche di registrazione. In: Crosilla F, e Dequal S (a cura di) Laser Scanning Terrestre, Collana di Geodesia e Cartografia, 008, International Centre for Mechanical Sciences, Udine, 39-53

Besl PJ, Mc Kay ND (1992) A method for registration of 3D shapes. IEEE Trans Pattern Anal Mach Intell 14(2):239-256

Brinckmann AE (1931) Theatrum Novum Pedemontii: Ideen, Entwürfe und Bauten von Guarini, Juvarra. Vittone vie anderen bedeutenden Architekten des piemontesischen Hochbarocks, Düsseldorf, p 96

Chen Y, Medioni GG (1992) Object modelling by registration of multiple range images. Image Vis Comput 10(3):145-155

Optech, ILRIS-3D, Technical Specifications; http://www.optech.ca/ i3Dtechoverview-ilris.htm

Pommer R (1966) Eighteenth-century architecture in Piedmont: the open structures of Juvarra. Alfieri and Vittone New York University Press, New York, p 300 pp

Portoghesi P (1982) L'angelo della storia. Teoria e linguaggi dell'architettura, Editrice Laterza, p 96 pp

Sgrenzaroli M, Vassena G (2007) "L'approccio Virtual Scan" in Tecniche di rilevamento tridimensionale tramite laser scanner Volume 1 Introduzione generale. Starrylink Editrice, Brescia, pp 74-79

Wittkower R (1958) Art and Architecture in Italy: 1600-1750 (the Pelican History of Art Series). Penguin books, London, 428 pp 